\title{
La Sociedad Española de Antropología, Etnografía y Prehistoria (1921-1951)
}

Es evidente que desde hace algunos años las investigaciones sobre historia de la antropología española han alcanzado un desarrollo bastante notable; sin embargo, si se repasa la bibliografía disponible, podrá observarse que ha existido un marcado interés por historiar la etapa que, desde determinada perspectiva, se considera punto de partida de los estudios antropológicos con carácter científico, es decir, la segunda mitad del siglo XIX. En menor medida podemos encontrar trabajos sobre las primeras décadas del $\mathrm{Xx}$, relacionados casi exclusivamente con estudios sobre movimientos culturales y políticos de carácter nacionalista.

Pero es la larga etapa que se inicia tras el final de la Guerra Civil el momento de la historia contemporánea de España que menos ha interesado, por el momento, a los historiadores de la antropología. Las razones que explican esta situación son bastante sencillas. La historia de la antropología es todavía una línea de investigación joven en nuestro país; por tanto, quienes se interesan por ella desde una óptica global, lo hacen normalmente enfocando sus estudios hacia las etapas iniciales de ese desarrollo '. Por otra parte, aquellos que reivindican la historia de la antropología y el folklore desde una perspectiva nacionalista han rechazado, de manera casi general, el estudio de la antropología en la etapa franquista, por considerarla (con gran parte de razón) tanto aniquiladora de los caracteres culturales propios de sus respectivas autonomías como estéril en lo referente al desarrollo de estudios antropológicos válidos ${ }^{2}$.

1 Son contadas las excepciones. Nos referimos a los varios artículos biográficos sobre personalidades como Julio Caro Baroja y Claudio Esteva o a la extensa obra de Carmen OrTIZ sobre Luis de Hoyos Sáinz y la antropología española (Madrid: CSIC, 1987).

2 Nuevamente las excepciones se refieren a estudios de carácter biográfico, como los escritos sobre Barandiarán o Violant i Simorra. Pero, dentro de estas excepciones, debemos destacar especialmente la tesis doctoral inédita de Luis Calvo titulada La antropología en Cataluña (1915-1970), de 1989, centrada en Carreras Artau y el Arxiu d'Etnografia i Folklore de Catalunya, en la que se critica de manera clara y concreta este rechazo de la antropología de la etapa posterior a la Guerra Civil. 
El breve trabajo que ahora presentamos sobre la Sociedad Española de Antropología, Etnografía y Prehistoria (SEAEP) pretende, precisamente, acercarse al estudio parcial de esas décadas de nuestro siglo que apenas han sido abordadas por los especialistas. La SEAEP, pese a sus grandes limitaciones, se constituye en un interesante punto de flexión, al presentar una trayectoria vital marcada por el trauma de la guerra. El enfoque que emplearemos será eminentemente institucional y desde esta perspectiva podremos ver cómo la actividad de la Sociedad se configura en gran medida, superando su carácter privado, como el eje de la investigación antropológica (y sobre todo prehistórica) de carácter nacional durante los años 20 y 30 . Después de la guerra su situación será cada vez más difícil, viéndose obstaculizada y finalmente eliminada por la presión ejercida desde los ámbitos del CSIC que detentan el control de los estudios etnológicos y antropológicos.

La fuente principal de información que hemos manejado en nuestro estudio ha sido la colección de actas que la misma Sociedad publicó en su revista a lo largo de toda su existencia. Los originales de estas actas junto con la restante documentación de la SEAEP hasta 1942, se quedaron en el Museo Etnológico, tras la expulsión de la Sociedad por parte del director del Instituto Bernardino de Sahagún de Antropología y Etnología (del CSIC) a principios de 1943. Nunca recuperaron tales documentos, aunque hoy tampoco parecen encontrarse en el referido museo. Después del último año citado, y sin que podamos precisar la fecha concreta, la Sociedad trasladó su sede al Seminario de Historia Primitiva del Hombre, en la Facultad de Filosofía y Letras de la Universidad de Madrid. Tampoco se ha podido localizar la documentación generada durante esos años.

Sí disponemos de información sobre la Sociedad en la sección de Secretaría General del archivo del CSIC, entre la correspondiente al Instituto Bernardino de Sahagún y al Museo Nacional de Etnología, en la que se documentan las relaciones, primero cordiales y más tarde casi violentas, entre dicho Instituto y la Sociedad 3 .

Todavía se podría disponer de mayor cantidad de datos mediante el recurso de la historia oral, entrevistando a algunos de los personajes que pertenecieron o tuvieron relación con la Sociedad, pero ésta es una tarea que sobrepasa los límites de este breve trabajo.

La SEAEP se constituye el 18 de mayo de 1921, en una reunión celebrada en los locales del Museo de Antropología, Etnografía y Prehistoria (antiguo Museo del Doctor Velasco y actual Museo Nacional de Etnología), por iniciativa del director del mismo, Manuel Antón y Ferrándiz. Presidieron

3 La parte del archivo del CSIC que nos interesa se conserva en la Sección de Educación y Ciencia del Archivo General de la Administración en Alcalá de Henares. 
la reunión Rafael Salillas, el propio Antón y Francisco de las Barras. Según el acta de la sesión, a la misma acudió «un crecido número de naturalistas, médicos, historiadores, catedráticos de diferentes centros y cultivadores de las ciencias antropológicas en sus diversas ramas" ${ }^{4}$. La convocatoria se había realizado mediante una citación que contiene algunas de las claves que pretenden servir de orientación a la Sociedad. Sus primeros párrafos dicen:

Durante la última mitad del siglo anterior se han fundado multitud de instituciones permanentes con el título de Sociedades o Institutos de Antropología y Etnografía, en cuyo seno se armonizan y publican trabajos de los naturalistas, médicos, jurisconsultos, criminólogos, sociólogos, filósofos y políticos, que estudian los organismos del género humano relacionado con aptitudes intelectuales y morales en su génesis étnica nacional, para encontrar las leyes naturales de sus respectivas disciplinas científicas.

Acaso por algún residuo racial atávico, la nación española no ha logrado consolidar ninguna institución parecida [...]. Útil y patriótico ha de ser, por consiguiente, poner remedio a esta penuria nacional. Es, además, urgente. Lo pide no sólo el decoro científico, sino el espectáculo actual de las Sociedades de Antropología que despiertan de su forzosa parálisis durante el paroxismo de la guerra reciente, con ardientes anhelos de vida intensa para alcanzar la más pródiga eugenesia de sus generaciones nacionales y ofrecer al Estado su más científico concurso para la solución de los palpitantes problemas sociales?

Como se puede comprobar, el escrito recoge claramente la tradición antropológica de finales del XIX, que ve en la antropología una ciencia aglutinadora de los esfuerzos de muy diversas disciplinas, guiadas por las ciencias naturales y enfocadas hacia el estudio global del hombre. La referencia al carácter eugénico de dicha antropología, en realidad no tendrá ninguna representación en la Sociedad.

La citación que comentamos argumenta, como otra razón más para crear la Sociedad, la necesidad de unir esfuerzos y coordinar actividades para la organización del XV Congreso Internacional de Antropología y Arqueología Prehistóricas, que debía celebrarse (todavía sin fecha fija) en Madrid. Como veremos más adelante, este congreso acabaría teniendo lugar en Portugal.

La convocatoria tuvo eco y en la citada reunión de 18 de mayo quedó constituida la Sociedad, eligiéndose una primera Junta Directiva compuesta por las siguientes personalidades: Joaquín Sánchez de Toca, presidente; Rafael Salillas, vicepresidente; Ángel Pulido, vocal primero; Eduardo Hernández Pa-

4 SEAEP A. y M., I, 1922, p. 7. La revista de la Sociedad tiene, hasta 1933, paginación diferente para las actas y para las memorias. Las citas harán referencia siempre a las páginas de las actas.

5 Id., p. 5. 
checo, vocal segundo; Francisco de las Barras, tesoreso; Luis de Hoyos, secretario; Domingo Sánchez, bibliotecario; y Juan Cabré, vicesecretario ${ }^{6}$. Además, se aprobaron los estatutos, en los que se recoge la intención de hacer publicaciones, de organizar congresos y de formar colecciones museográficas. Indican, también, que «en caso de disolución, los bienes y valores de la Sociedad pasarán al Museo Nacional de Antropología», que aquélla tendrá su sede en los locales del museo y que ambos centros constituirán el Instituto Español de Antropología, «para efectos de relación con los Institutos análogos extranjeros»?

La primera sesión ordinaria (sesiones que tendrán periodicidad mensual) se celebra el 21 de noviembre de 1921. En ella, Sánchez de Toca justificó la aceptación de la presidencia, pese a no haberse dedicado específicamente a las ciencias antropológicas, por el hecho de presidir igualmente la Real Academia de Ciencias Morales y Políticas, cuyos estudios tenían, dijo, evidente relación con los de la Sociedad. Además, se comprometía a «solicitar de los poderes públicos la protección necesaria para el desarrollo de los estudios y trabajos a que ha de dedicarse la Sociedad y para el fin concreto de hacer posible la publicación que lleve fuera de España los resultados de la labor de la misma» ${ }^{8}$. Éste era, sin duda, el objetivo que pretendían alcanzar los organizadores de la SEAEP al otorgar la presidencia a Sánchez de Toca, personaje que gozaba de notable influencia en la vida social y política del momento.

Las sesiones de la Sociedad tendrán normalmente (y sobre todo hasta la Guerra Civil) un marcado carácter científico, no limitándose los socios a discutir sobre cuestiones internas, sino presentando comunicaciones (breves) o memorias (más extensas) sobre sus distintos ámbitos de investigación. Durante el primer año de 1922 (y fines de 1921) son de destacar, desde el punto de vista etnográfico, las aportaciones de Hoyos, que publica diversos trabajos a los que más adelante (al hablar sobre el órgano de expresión de la Sociedad) nos referiremos. Además, desarrollará una intensa labor en los distintos cargos que ocupa, primero como secretario y más tarde como presidente.

Ese primer año puede destacarse también por un hecho muy importante para la Sociedad y la etnología española en general. En la sesión correspondiente al mes de noviembre de 1922, Manuel Antón informa que la Sociedad ha conseguido que le sean entregadas las papeletas que recogen la información obtenida mediante la famosa Encuesta del Ateneo de 1901, cuyo

$6 \quad$ Id., p. 8.

7 Los estatutos fundacionales se reproducen en SEAEP A. y M., I, 1922, pp. 9-10.

8 Id., pp. 27-28. 
título completo era «Información promovida por la Sección de Ciencias Morales y Políticas del Ateneo de Madrid, en el campo de las costumbres populares y en los tres hechos más característicos de la vida: el nacimiento, el matrimonio y la muerte» 9. Luis de Hoyos presentó en esa misma sesión una breve pero interesante comunicación titulada «Un cuestionario de Demografía etnográfica», que explicaba el desarrollo y contenido de la encuesta.

Las gestiones para obtener las citadas papeletas habían sido encomendadas a Manuel Antón por la Junta Directiva de la Sociedad. Cuando en la sesión de 1 de mayo de 1922 informaba aquél sobre las buenas perspectivas para la cesión, Hoyos intervino para indicar la conveniencia de que la petición hecha al Ateneo se ampliara a la entrega de las carpetas que contenían las respuestas originales ${ }^{10}$. Como hemos visto, se obtuvieron las papeletas (que hoy se guardan en el Museo Nacional de Etnología), pero no las citadas respuestas originales que, desgraciadamente, han desaparecido.

También en 1922 la Sociedad solicita y consigue la primera subvención oficial del Ministerio de Instrucción Pública y Bellas Artes, que se mantendrá, no sin problemas, durante casi toda su existencia.

Por lo que hemos apuntado, se podrá comprobar que el primer año de funcionamiento de la Sociedad es especialmente fructífero a todos los niveles. El éxito se completa con la consecución de un elevado número de socios que, en estos primeros momentos, reciben la categoría de socios fundadores: son 84 en Madrid, 48 en provincias y 5 en el extranjero (entre estos últimos, Breuil y Frankowski), en total 137. Hay, mayoritariamente, catedráticos, doctores y licenciados en ciencias y letras, profesores de instituto, abogados, médicos e ingenieros, además de algunos maestros, militares y religiosos ". Esta variedad de profesiones y campos de estudio es semejante a la existente entre los componentes de la Sociedad Antropológica Española fundada por el Doctor Velasco en 1865, aunque en la SEAEP es mayor el número de catedráticos y profesores universitarios y menor el de médicos.

A finales de 1923 se ha incrementado la relación de socios en 102 más, entre los que se incluye un buen número de Institutos y Escuelas Normales de Maestros y Maestras. Este mismo año tendrá, sin embargo, un carácter triste para la Sociedad. La causa es el fallecimiento de Rafael Salillas, ocurrido el 23 de mayo. Por este motivo, José Antón Oneca elabora una necrología del maestro que constituye la memoria XIV del volumen de las Actas $y$ Memorias correspondiente a 1923. Precisamente en la misma fecha fallecía también, con sólo 23 años, Ángel Sánchez, hijo de Domingo Sánchez (se-
$9 \quad$ Id., p. 91.
10 Id., pP. 60-61.
11 Id., pp. 13-20. 
cretario de la SEAEP durante muchos años), naturalista como su padre y dedicado igualmente a la antropología física.

Siguiendo con la reseña de actividades, podemos señalar que el infatigable Luis de Hoyos, entonces secretario de la Sociedad, pidió a ésta, en la sesión del mes de marzo de 1924, que la misma colaborara en la «Exposición de los trajes regionales» que se encargaba de organizar bajo la presidencia del Conde de Romanones ${ }^{12}$. Dicha exposición se pensaba inaugurar para el mes de mayo de ese mismo año, aunque en realidad abriría sus puertas en abril de 1925. Por esta aparente premura de tiempo y debido a que no se había recibido invitación formal para esa colaboración, no hubo ninguna determinación al respecto, apuntando Hoyos, ante tal situación, la necesidad de esperar un momento más propicio que parece que no llegó a encontrarse.

La Sociedad continúa con su actividad normal durante estos años. La subvención anual por valor de 5.000 pesetas se mantiene, aunque al poco se reducirá; la revista sigue su ritmo, publicando mayoritariamente (como más adelante veremos) trabajos de antropología física y, sobre todo, prehistoria y arqueología, aunque a Hoyos y a César Morán, entre otros, se deben también interesantes estudios etnográficos.

En 1926 todavía se mantiene firme la idea de que el XV Congreso Internacional de Antropología y Arqueología Prehistóricas se va a celebrar en Madrid, tal y como se acordó - gracias a la iniciativa del Marqués de Cerralbo- en 1912 en Ginebra, donde Manuel Antón y Luis de Hoyos ostentaron la representación oficial española. Formaban parte del comité organizador de dicho congreso varios miembros de la Sociedad: Antón y Mélida, vicepresidentes; Hoyos, secretario; y Tormo, Obermaier, Barras de Aragón, Hernández-Pacheco, Bolívar y Cabré, como vocales ${ }^{13}$. Pronto veremos en qué terminaron estas ilusiones.

El mismo año de 1926 la Sociedad sufre un momentáneo quebranto económico al ver disminuidas a 3.000 las 5.000 pesetas de la subvención oficial (que se recuperan en 1929 para volver a las 3.000 poco antes de la guerra, cifra que se mantendrá hasta 1951). A ello se une, igualmente, el hecho de que sólo un tercio de los socios paga regularmente sus cuotas. Sin embargo, esto no supone una merma en sus actividades y ello a pesar de que a las sesiones ordinarias sólo acuden, normalmente, «diez o doce personas», el núcleo de la Sociedad ${ }^{14}$.

Lo que acabamos de apuntar se percibe con claridad leyendo las actas correspondientes a 1927, plenas de actividades e iniciativas. La primera es

\footnotetext{
12 Ibid., III, 1924, p. 32.

13 Ibid., V, 1926, p. 18.

14 Id., p. 18.
} 
una propuesta de Anacleto Cabeza para redactar «una Cartilla con instrucciones, que sirva de guía para la recolección y envío al Museo de Antropología de objetos de Antropología, Prehistoria y Paleontología Humana que, a lo menos en los servicios de carácter público se descubran» ". Después de discutir sobre la denominación más conveniente para dicha guía, deciden que se organicen dos grupos para su formación; uno de Antropología, dirigido por Barras, y otro de Paleontología humana llevado por Hernández-Pacheco. Este último no había estado presente en esta sesión y cuando Barras presenta, en el mes de octubre, unas cuartillas con las indicaciones propuestas para el manual, Pacheco interviene para manifestar que «creía enteramente ineficaces las instrucciones de referencia porque no podía pretenderse con ellas improvisar antropólogos que hiciesen excavaciones, midiesen cráneos e interpretasen los objetos sin otra educación antropológica» ${ }^{16}$. Hoyos se adhirió a esta opinión. Domingo Sánchez, por el contrario, señaló que «le parecía que estaban equivocados (...) con respecto a la significación de las mencionadas instrucciones, con las cuales no se trata de improvisar antropólogos, sino simplemente de indicar la conducta que deben seguir las personas no peritas cuando encuentren objetos antropológicos o prehistóricos, para evitar que éstos se estropeen o se pierdan». El presidente, Quintiliano Saldaña, apoyó esta argumentación; sin embargo, no parece que el proyecto saliera adelante.

Otras tres iniciativas más se plantean en 1927, que tampoco llegan a cuajar. La primera hace referencia al propósito del P. Barreiro de fundar una Sociedad de Etnografía en Oviedo (con otras personas a las que no cita), que bien podría ser una sección de la propia SEAEP ${ }^{17}$. La segunda se refiere a la intención de realizar «emisiones radiotelefónicas» (radiofónicas) para dar a conocer la Sociedad al público. Se hicieron todas las gestiones oportunas e incluso Manuel Antón redactó el guión; sin embargo, por pro-

15 Ibid., VI, 1927, pp. 9-10.

16 Id., p. 32.

17 Sí se crearía una sección de la SEAEP en Canarias, en los años 40, algunas de cuyas actas se publican en la revista. En Barcelona se había fundado en 1922 la Associació d'Antropologia, Etnologia i Prehistòria, cuyos primeros presidente y secretario fueron Telesforo de Aranzadi y Josep Maria Batista i Roca, respectivamente. Esta Asociación había seguido, en gran parte, el modelo de la SEAEP, pero tendrá una personalidad propia bastante clara y diferenciada, aunque su preferencia por los estudios prehistóricos es semejante a la madrileña. Sobre la sociedad catalana ver Luis Calvo Calvo, La antropología en Cataluña (1915-1970), Barcelona, 1989 (tesis doctoral inédita), pp. 592-602; y L. PERICOT Garcfa, «Un episodio en la Historia de la Etnología en España. L'Associació Catalana D'Antropologia, Etnologia i Prehistòria», Revista de la Universidad Complutense, 98 (1975), pp. 15-21. 
blemas de disponibilidad de tiempo en la empresa radiofónica, las emisiones no se llevaron a cabo.

La tercera iniciativa la motiva una circunstancia exterior a la Sociedad. En la sesión correspondiente al mes de septiembre, también de 1927, Ignacio Bauer Landauer - ex-presidente de la Sociedad e incansable donante de libros y objetos, sobre todo africanos ${ }^{18}$ - comunicó que

había oído hablar a varios miembros de la Junta de Investigaciones Científicas de Marruecos y Colonias de la conveniencia de formar un Museo Etnográfico Colonial, y que él [Bauer] había manifestado su creencia de que en este Museo de Antropología existía ya un importante núcleo de objetos etnográficos procedentes del extinguido Museo-Biblioteca de Ultramar y que, por lo tanto, creía que no había razón para crear otro centro análogo ${ }^{19}$.

Domingo Sánchez intervino para ratificar lo expuesto por Buaer, refiriéndose a la Exposición de Filipinas de 1887 y al Museo-Biblioteca de Ultramar que, con carácter permanente y hasta su desaparcición en 1906, reunió la mayor parte de los objetos mostrados en dicha exposición ${ }^{20}$. Por estas razones, se propuso que Bauer hiciera las gestiones oportunas con el fin de que el propuesto museo no se crease ex novo, sino que fuera potenciado el Museo Antropológico. El proyecto no llegó a más.

También en relación con la Junta de Investigaciones de Marruecos y Colonias (que había sido creada por R.D. de 23 de marzo de 1927), el secretario de la Sociedad, Domingo Sánchez, señaló en la sesión correspondiente al mes de marzo que, en el citado real decreto,

(...) entre las entidades encargadas de proponer los Vocales que han de integrar dicha Junta, figura una Sociedad de Antropología y Folklore y no se menciona la de Antropología, Etnografía y Prehistoria. Mas como no teníamos conocimiento de la existencia de una Sociedad de aquel nombre, cabía dudar de si dicha denominación dependía de un error de nombre o no, y en este último caso, la omisión de la nuestra tendría para nosotros no poca importancia ${ }^{21}$.

18 A Bauer se debe también la donación, en mayo de 1926, de tres cartas autógrafas de Darwin que se conservan en el Museo Nacional de Etnología (SEAEP A. y AM., V, 1926, p. 18).

19 SEAEP A. y M., VI, 1927, p. 28.

20 Ver al respecto Luis Ángel SÁNCHEZ GOMEZ, «La etnografía de Filipinas desde la administración colonial española (1874-1898)», Revista de Indias, vol. XLVII, núm. 179 (1987), pp. 157-185.

21 Id., p. 15. 
Encargaron a Bauer que se informase sobre el asunto. Obviamente, el Gobierno pretendía referirse a la SEAEP, aunque no tuviera demasiado clara su denominación. Finalmente, la Sociedad recibió una real orden con el encargo de que nombraran al citado vocal. En sesión extraordinaria de 6 de abril de 1927 se elige «por aclamación» a Ignacio Bauer Landauer. El ostentar dicha representación era muestra, evidentemente, de que la Sociedad gozaba de algún reconocimiento en el ámbito oficial, igual que por el hecho de recibir una subvención anual (que, sin embargo, irá disminuyendo en cuantía), No obstante, tampoco debemos considerar estos hechos como prueba de que el Estado apoyaba firmemente los estudios fomentados desde la SEAEP. Por el destacado prestigio de un número importante de sus miembros e incluso por la influencia de que gozaban, la Administración estuvo muy lejos de ayudar como debiera a la Sociedad. También se ha indicado, como muestra de ese pretendido reconocimiento oficial, el hecho de que la SEAEP tuviera derecho a tener representantes en las cátedras de las materias que le fueran afines. Esto es cierto, pero sobre la presencia en tribunales de cátedras sólo hay dos referencias en todas las actas. En 1933 les piden que nombren vocal y suplente para una cátedra de «prótesis dental» en la Facultad de Medicina de la Universidad de Madrid. Eligen a Barras y a Domingo Sánchez, pero no son tenidos en cuenta. En 1934 proponen otros dos vocales suplentes para sendas cátedras de Fisiología en las Universidades de Santiago y Salamanca. La nula consideración que se prestaba a tales propuestas llevó a Manuel Hilario Ayuso a decir que «en lo sucesivo no debería contestarse tales comunicaciones del Consejo Nacional de Cultura, puesto que éste no ha hecho caso alguno de las propuestas que, en uso de su perfecto derecho, ha elevado la Sociedad» ${ }^{22}$. Pese a todo, decidieron seguir contestando a las solicitudes.

Continuando con la trayectoria histórica de la Sociedad, podemos señalar que en 1928 se documenta un hecho que, aunque en apariencia resulta positivo para la misma, con el paso de los años se convertiría en el principal desencadenante de los acontecimientos que precipitan su decadencia. Nos referimos a la presentación y aceptación, como socio numerario, de José Pérez de Barradas. Más adelante trataremos con detalle todo lo relacionado con esta cuestión. Ahora, no obstante, podemos señalar que Pérez de Barradas saldría muy beneficiado un año después, en 1929, de una gestión realizada por la Sociedad: en la sesión correspondiente al mes de mayo Juan Cabré informaba sobre

(...) un acuerdo del Ayuntamiento de Madrid (...) por virtud del cual se crea un Centro o Sección de Investigaciones Prehistóricas, y se determina proveer por opo-

22 SEAEP A. y M., XIII, 1934, p. 258. 
sición la plaza de Director (...). [Sin embargo] (...) parece existir deliberado propósito de admitir a oposición para proveer dicha plaza solamente a funcionarios del Cuerpo de Bibliotecarios, y hasta limitarla a los Bibliotecarios municipales, criterio que el Sr. Cabré no estima acertado, puesto que, constituyendo la Prehistoria una rama muy interesante de las Ciencias Naturales, que exige conocimientos de Geología y Antropología, parecía lógico pensar que no debiera excluirse a los naturalistas de aquellas oposiciones ${ }^{23}$.

Se hicieron al respecto las gestiones oportunas, que tuvieron unos claros resultados positivos y especialmente para Pérez de Barradas, quien en la sesión del mes de marzo de 1930 comunicaba su acceso a la dirección del Servicio de Investigaciones Prehistóricas del Ayuntamiento de Madrid. La Sociedad no va a obtener, por el contrario, ningún beneficio de dicha iniciativa.

El año 1930 termina con un amargo sabor para la SEAEP. En la sesión de noviembre, el presidente, Anacleto Cabeza - quien, no obstante, decía hablar exclusivamente como socio- se dirigía a Cabré preguntando las razones por las cuales el ya varias veces citado XV Congreso Internacional de Antropología y Arqueología se había celebrado en Portugal y no en España, como estaba previsto. Éste, aunque reconoció pertenecer al comité organizador, aseguró no conocer las causas y añadió que «había asistido al mencionado Congreso de Portugal en unión de su hija, siendo ambos de los pocos españoles que concurrieron (...), ninguno de los cuales, por cierto, ostentaba representación del Estado español» ${ }^{24}$. Como no obtuvo una explicación concreta, Cabeza volvió a plantear la cuestión en la sesión de diciembre. Tampoco entonces se pudo sacar nada en claro, aunque hubo acuerdo en que debieron ser circunstancias ajenas al presidente y a los miembros del comité organizador, todos ellos personas entusiastas y de gran prestigio. Finalmente,

todos se limitaron a lamentar profundamente la desairada situación en que han quedado las instituciones antropológicas, arqueológicas y prehistóricas nacionales, y el Estado español, que no acertó o no pudo defender la realización, en nuestra patria, de aquel Congreso, cuya importancia científica y social no es posible desconocer. Además, convinieron en que no es menos lamentable el hecho de que España no estuviese oficialmente representada en la reunión de Portugal, con lo que se ha inferido agravio a la nación vecina, aun cuando haya sido involuntariamente ${ }^{25}$.

La declaración hecha por la Sociedad sintetiza la desilusión y la tristeza de quienes fueron decididos defensores de aquel proyecto. Evidentemente, el

\footnotetext{
23 Ibid., VIII, 1929, p. 17.

24 Ibid., IX, 1930, p. 84.

25 Id., p. 88.
} 
Estado no tuvo el mínimo interés en apoyar la iniciativa, aunque desconozcamos las causas concretas del fracaso.

Tampoco parece que faltaran dificultades, aunque no podamos especificarlas, en la celebración del homenaje a Manuel Antón y Ferrándiz - fundador de la primera Cátedra de Antropología, de la propia Sociedad y director del Museo-, fallecido el 4 de septiembre de 1929, que no pudo celebrarse hasta febrero de 1931. El acto tuvo lugar en el Museo Antropológico y no en Muchamiel (pueblo natal de Antón, en Alicante), como en principio se había propuesto. Según se recoge en las actas, «concurrió numeroso y selecto público, en el que destacaban muchas personalidades de gran prestigio en las distintas ramas de las ciencias antropológicas y sociológicas y representaciones de las principales entidades y corporaciones a que el Sr. Antón perteneció (...)» ${ }^{26}$. Domingo Sánchez leyó una extensa nota biográfica sobre Antón. A continuación intervinieron Francisco de las Barras (como sucesor de Antón en la cátedra y en la dirección del Museo de Antropología), Luis Lozano Rey (en representación del Museo Nacional de Ciencias Naturales), Antonio Zulueta (vicepresidente de la Sociedad Española de Historia Natural), Ignacio Bauer (asumiendo la representación de quienes fueron alumnos de Antón), Manuel Martínez Risco (por el Ateneo de Madrid), José Ramón Mélida, vicepresidente de la SEAEP, pero hablando en representación de la Real Academia de la Historia, y, por último, José Antón Oneca, en nombre de la familia de Antón ${ }^{27}$.

Con la muerte de Manuel Antón se cerraba un período fundamental en la historia de la antropología española, y el homenaje supuso el reconocimiento pleno de la importante labor por él desarrollada.

Antón y Ferrándiz había consolidado la antropología naturalista en nuestro país, entre otras razones al conseguir que se dotara la primera cátedra de antropología (en la Facultad de Ciencias de Madrid) en 1892. Cuarenta años después, en 1932, la SEAEP intentará, sin éxito, que se cree una Cátedra de Etnología, para completar así la institucionalización en la universidad de todas las ramas de las ciencias antropológicas, al existir ya cátedras de antropología física y prehistoria. La iniciativa parte, además, de un prehistoriador, Julio Martínez Santa-Olalla, con motivo de informar a la Sociedad sobre la consulta hecha en la Facultad de Filosofía por el Ministerio de Instrucción Pública para organizar una Sección de Geografía, con su correspondiente licenciatura y doctorado. En su intervención, señaló Santa-Olalla

\footnotetext{
26 Ibid., X, 1931, p. 12.

27 Id., pp. 13-34.
} 
que:

Incumbe, por lo tanto, a la Sociedad el pedir que la Antropología y Prehistoria, de que existen cátedras, sea elemento indispensable [en los estudios de geografía], y que se cree la cátedra que desde largos años falta, como el Sr. Obermaier hizo con sobrada razón notar en 1926, al ingresar en la Academia de la Historia: una Cátedra de Etnología (...) ${ }^{28}$.

Como era lógico, la Sociedad aceptó la propuesta de solicitud de cátedra, que se dirigió directamente al Ministerio de Instrucción Pública. Se encargaron de su redacción Obermaier, Manuel Maura y Santa-Olalla. El texto fue presentado y aprobado en la sesión de 14 de diciembre de 1932, y decía, tras los preliminares, lo siguiente:

4. 2 La Sociedad cree absolutamente imprescindible el que las enseñanzas profesadas en las Cátedras de Antropología e Historia Primitiva del Hombre (Prehistoria), figuren en el plan de estudios de dicha Sección de Geografía (...).

5.^ (...) la Sociedad (...) no puede menos de hacer resaltar una necesidad, de largo tiempo sentida, para los estudios modernos antropológicos, prehistóricos, geográficos e históricos en general: la Etnología (...).

6. Los estudios de Etnología no deben abarcar tan sólo el monográfico y descriptivo de los pueblos (Etnografía), sino que también se han de ocupar de Psicología Étnica, las culturas, caracteres morales y sociales, etc. ${ }^{29}$.

No hay referencia en las actas a que se recibiera respuesta a este escrito y, como es notorio, no se creó cátedra alguna de Etnología. Habría que esperar otros cuarenta años más para que esto ocurriera, en 1972, cuando Claudio Esteva consiguió que se dotara una cátedra de Antroplogía Cultural en la Universidad de Barcelona.

Siguiendo con nuestro relato, podemos constatar que en esta primera etapa de la Sociedad (hasta la Guerra Civil), los años de 1934 y 1935 reflejan cierto decaimiento en su actividad. Aparte de no publicarse en esos dos años ningún artículo de carácter etnográfico en la revista, son las propias actas de las sesiones las que nos señalan esa situación. Las reuniones se limitan, prácticamente, a la lectura de conferencias. Los debates, las discusiones y la información sobre actividades se reducen al mínimo. La situación parece preludiar los difíciles momentos que va a tocar atravesar a la Sociedad y al conjunto del país.

El inicio de la Guerra Civil paraliza sus actividades, al menos eso es lo que debemos pensar, ya que no se publicará -en el volumen único de 1936 -

28 lbid., XI, 1932, p. 55.

29 Id., pp. 59-60. 
1940 - ningún acta del período que va de junio de 1936 a septiembre de $1939^{30}$.

No sólo parecen cesar las reuniones, sino que se suspende la edición de la revista, que reaparece con el citado tomo único de 1936-40 (bajo el título de Atlantis) en el que únicamente se incluyen memorias, aplazando para el tomo XVI (de 1941) la publicación de las actas correspondientes a 1936, 1939 y 1940. En el citado tomo XV, Martínez Santa-Olalla se refiere al período de inactividad en los siguientes términos: «Empalmamos directamente con el 18 de julio de 1936, ya que entonces cesamos voluntariamente en nuestras actividades sociales y destruimos las publicaciones en prensa para no contribuir al prestigio del asesinato, convertido en norma de un régimen» ${ }^{3 !}$.

Por el momento es imposible valorar las palabras de Santa-Olalla y comprobar cuál fue en realidad la situación vivida por la Sociedad durante la guerra. En cualquier caso, es evidente que muchos de sus miembros son partidarios a ultranza del nuevo régimen, con el mismo Santa-Olalla al frente ${ }^{32}$. Será éste quien tome las riendas en la nueva etapa de la Sociedad en todos

30 Tampoco parece que el propio ambiente de la Sociedad fuera muy apacible en los meses previos al conflicto bélico. En las actas correspondientes a enero y abril de 1936 se recogen, aunque mínimamente, las tensiones habidas al rechazarse la publicación de un extenso artículo biográfico de Domingo Sánchez sobre Ramón y Cajal. Puede que hubiera otras razones para esta negativa, además de las defendidas por la presidencia sobre el número de páginas y la especialización científica del biografiado. Presidía entonces la Sociedad Julián de la Villa (catedrático de Anatomía), quien, según Caro Baroja, «no podía ver a Ramón y Cajal» (Los Baroja, Barcelona: Círculo de Lectores, 1986, p. 233). El mismo Julio Caro comenta la impresión que le causaba el ambiente que se respiraba durante esos años: «(...) sesiones semejantes y otras me hicieron adquirir una idea poco grata de la gente vinculada por una profesión. $\mathrm{Y}$ así llegué a ser un socio que utilizaba más la biblioteca que otra cosa. Me asombraba ver a hombre mayores poner pasión en discusiones de detalle que, a la postre, lo mismo daba que terminaran de una manera que de otra» (Id.).

31 Atlantis, XV, 1936-40, p. 7.

32 Caro Baroja se refiere a Santa-Olalla en los siguientes términos: «Éste había vivido en Alemania y llegó a Madrid con mucho prestigio. Era un joven alto, rubio, muy miope, que, en general, era bueno con los alumnos, pero áspero con sus colegas. Éstos le tenían antipatía. Santa-Olalla hablaba de una manera irónica, desdeñosa y lánguida a la par (...). Yo me lo encontré por casualidad en Madrid después de la guerra, y pese a las circunstancias y antecedentes estuvo amable conmigo, cosa que no era del todo común, y más en un hombre de su origen e ideología. En efecto, Santa-Olalla era hijo de un general (...). Unos hermanos de él habían actuado en la Falange y habían sido paseados o muertos en circunstancias trágicas. Él estuvo refugiado en una embajada y salió en un estado de ánimo imaginable de hostilidad hacia la gente del bando contrario (...). Tenía mucha erudición, sensibilidad acaso hipertrofiada, gana de agradar en casos y una agresividad rara en otros» (Op. cit., p. 354). 
los ámbitos, asegurándose, además, el control de la revista, de la que pasa a ser director hasta su desaparición. Esta etapa va a estar inevitablemente marcada por el espíritu fascista del nuevo Estado, aunque pronto otro tipo de cuestiones vayan a interesar y preocupar a la Sociedad. Las páginas de presentación del volumen $\mathrm{XV}$ de la revista son bien significativas. Comienzan con una dedicatoria al «Generalísimo de los Ejércitos» (con un retrato de Franco) y otra a los «caídos por Dios, por España y su revolución nacionalsindicalista», con los nombres de ocho socios muertos en el bando «nacional» durante la guerra. Siguen unos párrafos de Santa-Olalla que reflejan el intento (que no pasará de ahí) de utilizar las ciencias antropológicas para «mejorar la raza» y «engrandecer la patria». Entre otras cosas, puede leerse lo siguiente:

Al reaparecer es para continuar un trabajo que jamás se hizo vuelto de espaldas a la realidad de los imperativos hispánicos, contenidos en nuestros apelativos sociales de Antropología, raza y espíritu hispánicos; Etnografía, presencia de España en los Continentes, y Prehistoria, raíces de la Hispanidad.

Tras la Victoria, y en la obligación revolucionaria que ante nosotros tenemos, las ciencias a que se dedica esta Sociedad han de alcanzar un gran desarrollo. Pues es indispensable conocer a fondo el pueblo y lo que en él hay de verdaderamente tradicional y averiguar los componentes de nuestra estirpe, como lo hace la Antropología (...). Finalmente, la Etnografía, nos hará ver la grandeza de un Imperio, sin igual en la Historia, y las posibilidades de otro ${ }^{33}$.

La primera sesión celebrada tras el final de la guerra, el 7 de septiembre de 1940, refleja claramente el momento que vive la Sociedad y España entera:

El Presidente [Julián de la Villa] abre la sesión, primera que se celebra después del Alzamiento Nacional, haciendo constar la adhesión de la Sociedad al Caudillo y al Movimiento Nacional y la forma ejemplar en que nuestra Sociedad cesó voluntariamente en su vida para no facilitar a los rojoseparatistas el elemento de propaganda que para ellos constituía cualquier actividad científica.

Dedicó unas sentidas frases de elogio a los Mártires de la Sociedad asesinados por los rojoseparatistas y dio lectura a los nombres de los caídos, contestados, brazo en alto, con el $i$ Presente! (...).

Se decidió imprimir una circular a fin de hacer un recuento de socios, la depuración oportuna en ciertos casos y exclusión de la Sociedad de los rojoseparatistas destacados ${ }^{34}$.

Pero, como ya hemos indicado, estos primeros propósitos de recuperar la «grandeza imperial» de España a partir de los estudios antropológicos, pronto van a ser sustituidos por una lucha desesperada para lograr la propia

\footnotetext{
33 Atlantis, XV, 1936-40, p. 8.

34 Ibid., XVI, 1941, p. 282.
} 
supervivencia de la Sociedad. Nunca fue brillante su economía, pero ahora, en los primeros años de la postguerra, la situación es aún peor. Pese a las numerosas solicitudes hechas al Ministerio de Educación (como pasa a denominarse el antiguo de Instrucción Pública), no consiguen que se incrementen las 3.000 pesetas que reciben. Ante esta situación, buscan un cauce alternativo y lo encuentran en el recién creado Consejo Superior de Investigaciones Científicas, con quien firman un acuerdo el 16 de julio de 1940 por el cual la Sociedad se anexiona al Patronato «Menéndez Pelayo», gozando de cierta autonomía y recibiendo el apoyo económico necesario para seguir publicando la revista ${ }^{35}$. Por esta razón, los tomos correspondientes a 1936-40 y 1941 llevarán por título Atlantis. Actas y Memorias de la Sociedad Española de Antropología, Etnografía y Prebistoria y Museo Etnológico Nacional, ya que la propuesta de la SEAEP fue hacer que la revista se erigiera en órgano de expresión tanto de la Sociedad como del Museo Etnológico, que había cambiado su antigua denominación de Museo Antropológico y pasaba a depender ahora del CSIC.

Para la Sociedad era obvio que su continuidad dependía, en gran medida, de estas relaciones. Pero el acuerdo pronto se vendría abajo. Con fecha 10 de enero de 1941 recibían un escrito firmado por el secretario del Patronato «Menéndez Pelayo» en el que se les comunicaba que debían dejar de publicar artículos sobre arqueología y prehistoria en la revista Atlantis (subvencionada, recordemos, por el CSIC), ya que dichas materias eran propias de otra revista del Consejo, el Archivo Español de Arqueologia ${ }^{36}$. Este oficio tuvo su origen al comprobarse en el Patronato que en el tomo XV de Atlantis (de 1936-40), cuatro de los siete artículos que contenía versaban sobre arqueología, así como ocho de las catorce «noticias». Además, en ese mismo tomo aparecía una reseña de Pérez de Barradas sobre una obra de Breuil que ya había sido publicada en el Archivo Español de Arqueología.

La gravedad del problema llevó a que el presidente de la Sociedad, el Marqués de Lozoya (que era al mismo tiempo Director General de Bellas Artes) reuniera a la Junta Directiva en su despacho oficial. Todos los miembros de dicha junta estuvieron de acuerdo en rechazar el ultimatum del CSIC. El presidente aseguró, por su parte, «que no veía la posibilidad de un acuerdo intermedio: o la Sociedad seguía el critero expresado por el $\mathrm{Pa}$ tronato, o tenía que separarse del mismo" ${ }^{37}$. Como, efectivamente, no hubo

\footnotetext{
$35 \quad$ Id., p. 518.

36 Id., pp. 516-517.

37 Id., p. 519.
} 
acuerdo, el Marqués de Lozoya, «dado lo tirante de su situación», presentó la dimisión, aunque prometió seguir colaborando como simple socio ${ }^{38}$.

El conflicto con el CSIC no supuso, sin embargo, la separación oficial de la Sociedad respecto al Patronato, aunque de hecho se congelaron las relaciones. La SEAEP quiso aprovechar esta especie de compás de espera para intentar solucionar su futuro económico, y así, después de transcurrido un año desde el comienzo de las tensiones, el secretario, Julio Caro Baroja, inició una serie de gestiones ante el Secretario General del CSIC (J. M. ${ }^{{ }^{2}}$ Albareda) para continuar con la cooperación. Como parecía que el Consejo tenía cierto interés en el proyecto, la Junta Directiva redactó unas «bases de colaboración», con fecha 24 de marzo de $1942^{39}$. En ellas se propone que la Sociedad continúe e intensifique «su vida social bajo el patronato del Consejo Superior de Investigaciones Científicas» y se solicita una subvención anual de 40.000 pesetas para la revista, que elevaría su tirada de 700 a 1.000 ejemplares, 400 de los cuales se entregarían al CSIC. Además, la Sociedad «renuncia a favor del Consejo la venta de su revista, tanto la directa como la que tenga forma de suscripción».

Sin embargo, transcurren los meses y no se recibe respuesta. Para intentar acercar posiciones, en la sesión del mes de octubre de ese mismo año, 1942, se "propone que el Director del Instituto Bernardino de Sahagún [de Antropología y Etnología] [IBS] sea nombrado Vocal nato de la Sociedad, a fin de que el Consejo Superior de Investigaciones Científicas esté debidamente representado en la Directiva» ${ }^{40}$. La intención era buena, ya que se preveían los problemas que podían surgir con el Instituto, pero no sirvió de nada.

No obstante, en un principio el CSIC aprobó las bases de colaboración. Fue la intervención de Pérez de Barradas la que determinó la suspensión del acuerdo. Los datos nos los ofrece el mismo Pérez de Barradas en una carta dirigida al Secretario General del CSIC, con fecha 30 de octubre de

38. Esta situación ponía a la Sociedad ante un futuro económico muy incierto. Pese a todo $-\mathrm{y}$ gracias, entre otras razones, a una subvención de mil pesetas concedida por el Ayuntamiento- consiguen publicar el primer volumen -que será el único- de la Corona de estudios que la Sociedad Española de Antropología, Etnografía y Prebistoria dedica a sus mártires (1941), editado por Santa-Olalla. Son en total 32 artículos, todos -excepto dos- de temática arqueológica.

39 A. y M. de la SEAEP, XVII, 1942, pp. 210-212.

40 Id., p. 212. El director de dicho Instituto y del Museo Etnológico era José Pérez de Barradas, quien también pertenecía a la Sociedad desde años atrás. El «Bernardino de Sahagún» se creó en 1941 y pervivirá hasta finales de los años 60. Contó con secciones en Valladolid (de escasa importancia) y en Barcelona, ésta con Santiago Alcobé a su frente. 
$1942^{41}$. Por este escrito sabemos que el 11 de junio el Comité Ejecutivo del Consejo había aprobado la subvención para la revista de la Sociedad, que se concedía como «ampliación de la dotación» del IBS. Barradas se negaba a dar conformidad a este gasto, así como «a aceptar la responsabilidad de una revista que personalmente no dirige». Además, decía, «resultaría beneficiada la Sociedad con los cambios con revistas similares en detrimento del Instituto y por lo tanto del Consejo». Por todo ello solicitaba que le fuera encomendada la dirección de la revista.

Parece que en un primer momento el CSIC decidió continuar adelante con la colaboración y no tuvo en cuenta las indicaciones de Barradas; sin embargo, éste se encargaría de trastocar la situación. Las actas publicadas en su revista por la Sociedad no contienen ninguna información al respecto, pero podemos conocer lo ocurrido acudiendo al archivo del Consejo. En éste hemos encontrado la copia dirigida al CSIC (el original se remitió al Ministerio de Educación) de un extenso informe de la Sociedad, fechado a 12 de febrero de 1943, en el que se exponen con detalle todos los problemas existentes ${ }^{42}$. El escrito hace un recorrido por la vida de la Sociedad y señala que, pese a haber sido aprobada la subvención de 40.000 pesteas, Barradas se negó a dar el conforme a las facturas de gastos correspondientes a la publicación de las actas. Ante tal situación, Santa-Olalla solicitó entrevistarse con el citado Pérez de Barradas, lo que consiguió finalmente el 21 de diciembre de 1942. El relato del encuentro y de los acontecimientos posteriores tiene aires de crónica de sucesos:

Al llegar el Sr. Pérez de Barradas que era esperado por el Sr. Martínez SantaOlalla, fue éste agredido de obra por aquél, sin haber mediado palabra ni discusión alguna, con la natural sorpresa ya que el agresor era el director del establecimiento que de tal suerte olvidaba elementales deberes de caballerosidad, y del decoro que por razón de su cargo y del lugar en que se encontraba venía obligado a guardar, demostrando una falta de consideración y respeto cuya calificación encomendamos al recto criterio de V.E.

Tras este penoso incidente en que el aludido Sr. Pérez de Barradas quiso arrojar de nuestro domicilio social al secretario y dijo arrojaba a la Sociedad, desconociendo así la limitación de sus atribuciones y derivando una cuestión esencialmente privada hacia toda una entidad, que por su carácter, fines y componentes debía merecerle la máxima consideración, esperaba la Sociedad dejando de lado el aspecto personal que no le incumbe, una rectificación y excusas que no se han producido, antes al contrario han sido obligadas a dimitir antes y después del in-

41 Archivo del CSIC, caja 591, s/n. En AGA-EC, caja 8537, s/n.

42 Archivo del CSIC, caja 594, s/n. En AGA-EC, caja 8540, s/n. 
cidente personas que dependían del Instituto Bernardino de Sahagún y ocupaban desde hace muchos años puestos directivos, e incluso el propio ordenanza ${ }^{43}$.

Tras este incidente y cuando el 27 de enero de 1943 los miembros de la Sociedad acudieron al museo para celebrar la primera sesión del año, se encontraron con el edificio cerrado. Ante tales hechos solicitaban que les fuera permitido el acceso al museo y a los libros y ficheros que allí guardaban, que se reconociese el carácter de depósito de la biblioteca y que se hiciese entrega de las 40.000 pesetas concedidas como subvención a la revista. Ninguna de las peticiones sería satisfecha. Es más, el propio Pérez de Barradas se dirigía al Presidente del CSIC con fecha 10 de marzo de 1943, solicitando que la biblioteca de la Sociedad fuera incorporada, en propiedad, al IBS. Basaba su argumentación en el hecho de que, debido a las subvenciones del Ministerio y luego del Consejo, dicha biblioteca pertenecía «en justicia» al Estado ${ }^{44}$. Esto fue efectivamente lo que se hizo, aunque más bien parece que por iniciativa personal de Barradas que por decisión del CSIC. Decimos esto porque todavía en dos ocasiones más el Consejo ofreció su colaboración y apoyo a la SEAEP. El 4 de julio de 1944 se la invita a participar en la nueva publicación periódica del IBS (los Trabajos del Instituto Bernardino de Sabagún) al tiempo que les informan de la concesión de 20.000 pesetas en concepto de subvención para la revista Atlantis (siguen llamando así a la revista de la Sociedad) ${ }^{45}$. Por otra parte, el 16 de julio de 1945 (con las remozadas instalaciones del museo recién inauguradas) el Secretario General del Consejo (J. M. ${ }^{a}$ Albareda) se dirigía a la SEAEP informándola de haber remitido un oficio al director del Museo Etnológico (Pérez de Barradas) instándole a que dispusiera el local necesario en dicho museo para instalar la biblioteca y demás servicios de la Sociedad» ${ }^{46}$. Tam-

43 Id., ff. 9-10. Caro Baroja dice lo siguiente respecto a la vida de la Sociedad durante esos años y al incidente que acabamos de presentar: «Al comienzo [concluida la guerra civil], la Sociedad de Antropología volvió a funcionar como antes, y yo fui creo que hasta vicesecretario. Luego, los que formaban la plana mayor empezaron a disputarse cargos y preeminencias y terminaron a la greña. Bajo los retratos de sus fundadores vi yo darse de tortas a dos arqueólogos conocidos, amigos íntimos hasta la víspera, por una credencial de unos miles de reales, por no decir pesetas» (op.cit., p. 358). Y más adelante apunta: «Poco a poco fui alejándome, porque, además, se plantearon desavenencias entre la dirección del Museo y la de la Sociedad de Antropología. Se dividieron las bibliotecas [en realidad el IBS se adueñó de la perteneciente a la SEAEP], siempre unidas, y la tensión llegó a un grado extremo. A mí me cogía entre dos fuegos y decidí ir apartándome de los dos» (op. cit., p. 400).

44 Archivo del CSIC, caja $594 \mathrm{~s} / \mathrm{n}$. En AGA-EC, caja 8540, s/n.

45 Archivo del CSIC, caja 598, s/n. En AGA-EC, caja 8543, s/n.

46 Archivo del CSIC, caja 602, s/n. En AGA-EC, caja 8547, s/n. 
poco estas últimas disposiciones se pondrán en práctica. Nunca más la SEAEP tendrá acceso ni a su biblioteca ni a la documentación que guardaba en el museo.

Pese a todo, logra subsistir y mantener sus reuniones. Desconocemos el lugar en que se celebran durante estos años, aunque parece que desde 1949, o quizá antes, lo hacen en el Seminario de Historia Primitiva del Hombre, en la Facultad de Filosofía y Letras de la Universidad de Madrid. Aunque el número de socios es alto (262 en 1944), la intensidad de las sesiones decae, apenas hay debates y se reducen (al igual que en el período de 1934-35) a la lectura de conferencias. En la correspondiente al mes de enero de 1945 se decidió dejar sin efecto el acuerdo de 28 de octubre de 1942 por el que se nombraba vocal nato de la Sociedad al director del IBS, es decir, a Pérez de Barradas. La decisión sólo podía tener un carácter testimonial.

Como era de esperar, los problemas económicos fueron cada vez más acuciantes. A comienzos de 1947 solicitaban sendas subvenciones al Ministerio de Asuntos Exteriores y al Instituto de Cultura Hispánica. Ninguna les es concedida. A tales dificultades se unen las de índole administrativo, debido a las trabas de todo tipo y hasta prohibiciones que sufren por parte de distintos centros oficiales, especialmente en lo que se refiere a permisos de salida para asistir a congresos en el extranjero y de entrada para investigadores invitados.

Desde esas mismas fechas (1947), en buen número de actas de sesiones se hace constar la protesta de la Sociedad por verse privada de sus locales, colecciones y biblioteca. En la de 27 de octubre de 1948 dejan escrito:

La Sociedad hizo constar una vez más su protesta ante el estado de cosas que supone la imposibilidad de utilizar sus locales sociales en el Museo Antropológico del doctor Velasco (actualmente Museo Etnológico) y el secuestro de la biblioteca y la gran cantidad de libros y revistas de nuestra propiedad (...). Igualmente la Sociedad reitera su protesta porque de las colecciones propiedad de la Sociedad se haya dispuesto contra nuestra voluntad sin la menor consulta, y unos objetos hayan sido instalados en el antiguo Museo del doctor Velasco y otros hayan sido entregados, contra todo derecho, al Museo Arqueológico Nacional ${ }^{47}$.

Al año siguiente, en 1949, se intenta conseguir de manera efectiva la devolución del citado patrimonio, para lo que se dirigen por escrito al Se-

${ }^{47}$ A. $y$ M. de la SEAEP, XXIII, 1958, p. 212. Como se puede comprobar, la Sociedad se refiere siempre al «antiguo Museo Antropológico» o al «antiguo Museo del doctor Velascon, como intentando negar validez a la nueva etapa que vive el museo bajo la dirección de Pérez de Barradas, que se corresponde también con una nueva denominación, la de Museo Etnológico. 
cretario General del CSIC. Acuden al museo, acompañados de un notario, el 21 de mayo, pero Pérez de Barradas argumenta no poder hacer entrega de objeto alguno sin una orden del CSIC. Sin embargo, pese a que el Secretario del Consejo les asegura por escrito que no habría inconveniente en hacer la entrega, ésta no se llega a realizar ${ }^{48}$. Pero no es éste el único problema que asedia a la Sociedad en este difícil año. Las dificultades económicas continúan en alza. Se ven obligados a devolver numerosos originales (sobre todo extranjeros) enviados para su publicación, y no consiguen que el Ministerio de Educación aumente la subvención. Siguen repitiéndose las trabas administrativas que motivan, entre otras cosas, que Santa-Olalla no pueda asistir al III Congreso de la Conferencia Internacional de Africanistas Occidentales, pese a ser representante oficial de España en el comité.

En 1949, y dada la especialísima situación que atravesaba la Sociedad desde 1943, deciden renovar los estatutos y el reglamento. Lo más significativo de los primeros es su artículo $13 .^{\circ}$, que dice: «En caso de disolución, los bienes y valores de la Sociedad pasarán al Seminario de Historia Primitiva del Hombre o, en su defecto, a la Facultad de Filosofía y Letras de la Universidad de Madrid». Por lo que se refiere al nuevo reglamento, se incluye un artículo transitorio que dice así:

La Sociedad Española de Antropología, Etnografía y Prehistoria se reserva cuantos derechos puedan derivarse de sus antiguos Estatutos y Reglamentos y domicilio en el antiguo Museo Antropológico del Dr. Velasco. Igualmente (...) se reserva, si en su día hubiera lugar, la reclamación de cuantos daños y perjuicios se le hubieran originado por una situación de hecho unilateral impuesta por la fuerza ${ }^{49}$.

Es evidente que la Sociedad no tiene ya, a estas alturas, esperanza alguna de recobrar su patrimonio perdido. José Pérez de Barradas, director del IBS y del Museo Etnológico, que había obtenido grandes beneficios de la Sociedad mientras fue socio, les impedía cualquier progreso en ese y otros muchos sentidos. Y ya que no podían hacer otra cosa, la Sociedad se permitió incluir en su revista una severísima reseña enviada por Juan Comas sobre el Manual de antropología publicado por Barradas en 1946, que suponía una demoledora crítica de la obra, de la que son una muestra sus párrafos finales: «El Manual de Antropología de Pérez de Barradas es el tipo más acabado que hemos visto nunca de lo que llamaríamos cómo no debe escribirse un Manual de Antropología, o lo que no debe ser un

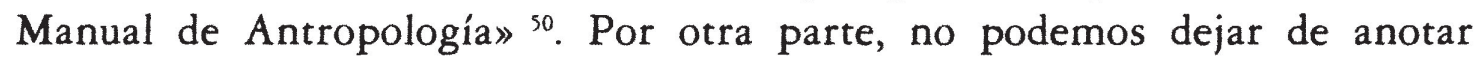

\footnotetext{
48 Ibid., XXIV, 1949, pp. 146-149.

49 Id., p. 163

so Id., pp. 104-109, cf. 109. El subrayado es del autor.
} 
que de no haber existido el conflicto entre la Sociedad y Barradas, la reseña no hubiera sido publicada, no sólo por la dureza sino por las avanzadas ideas manifestadas por Comas, que nada tenían que ver con las defendidas oficialmente por la SEAEP.

La vida de la Sociedad durante estos últimos años es una lenta y cruel agonía. La escasez de fondos obliga a que la transcripción de las actas deba resumirse al máximo, lo que da a la revista un tono bastante pobre; además, las sesiones se reducen prácticamente a anunciar alguna conferencia, a protestar por el secuestro de sus bienes y a informar negativamente acerca de las gestiones para recibir nuevas subvenciones. Con fecha 9 de febrero de 1950 solicitan del Ministerio de Educación 50.000 pesetas anuales, en un escrito que se reitera en varias ocasiones, obteniendo unas veces la callada por respuesta y otras recibiendo notificación de que el texto anterior de referencia se ha extraviado. Se busca cualquier otro tipo de solución alternativa, proponiéndose, incluso, que las Actas y Memorias pasen a ser el órgano de expresión de la Sección de Historia Primitiva del Instituto de Estudios Madrileños.

Las dificultades económicas anulan todos los esfuerzos. En la sesión correspondiente al mes de noviembre (penúltima de la que existe constancia en las Actas), el secretario y alma de la SEAEP, Julio Martínez SantaOlalla, «se manifiesta disconforme con la falta de intensidad de la vida de la Sociedad, y considerándose en parte responsable de la misma, propone a los socios se le sustituya» ${ }^{51}$. La Junta no aceptó la dimisión, aunque decidieron estudiar el asunto en otras sesiones; sin embargo, en la última, de diciembre de 1951, no se toca el tema. Desconocemos si la Sociedad continuó sus actividades después de esa fecha, pero lo cierto es que el tomo XXV de las Actas y Memorias, correspondiente a este año de 1951, es el último que se publica.

Después de este repaso cronológico a la vida de la Sociedad y antes de apuntar conclusiones sobre la misma, conviene que hagamos una breve referencia al contenido científico de su revista. Ésta presenta tres etapas fundamentales - siguiendo el desarrollo de la SEAEP - que se reflejan en su título. La primera denominación, en realidad no es más que el nombre de la Sociedad, seguido de los dos sustantivos que definen su contenido: Sociedad Española de Antropología, Etnografía y Prehistoria. Actas y Memorias. Así se mantiene desde el tomo I (1922) hasta el XIV (1935). La nueva etapa que se abre tras la Guerra Civil y el entronque con el CSIC llevan a variar el título, con una primera referencia escueta, seguida de la denominación amplia: Atlantis. Actas y Memorias de la Sociedad Española

s1 Ibid., XXV, 1951, p. 115. 
de Antropologia, Etnografía y Prehistoria y Museo Etnológico Nacional. Este nombre aparece únicamente en los tomos XV (1936-40) y XVI (1941). La referencia al Museo Etnológico es obvia: pretenden formar con él (que depende del CSIC como ya vimos) una sola entidad y por ello la revista se define como órgano de expresión de ambos centros.

La creación del Instituto «Bernardino de Sahagún» de Antropología y Etnología en el seno del CSIC, en 1941, y el hecho de que su dirección (como la del museo) la detente Pérez de Barradas, supondrán (junto con otras cuestiones menores) un obstáculo insalvable para la unión, o al menos la colaboración entre el CSIC y la Sociedad. Aunque en distintos momentos parece posible el reinicio de la cooperación, lo cierto es que ésta no se produce. La revista deja entonces de hacer referencia al Museo, así como de incluir la palabra Atlantis, queda simplemente como Actas y Memorias de la Sociedad Española de Antropología, Etnografia y Prebistoria, desde el tomo XVII (de 1942) hasta el XXV, y último, de 1951.

Estas tres etapas que hemos marcado pueden reducirse a dos en cuanto al contenido científico de la revista: de 1922 a 1935 y de 1936 a 1951, es decir, antes y después de la guerra. A continuación, y sólo a título orientativo, señalamos la temática de los artículos publicados en cada tomo. Hemos distinguido tres grandes áreas: 1. ${ }^{a}$ Antropología física (A), con estudios la mayor parte de ellos sobre osamentas y menos sobre individuos vivos; 2." Etnografía (E), estudios de carácter descriptivo o interpretativo sobre España y otros países, incluyendo trabajos histórico-etnográficos; $3 .{ }^{2}$ Prehistoria $(\mathrm{P})$, con artículos de temática estrictamente prehistórica o solamente arqueológica. No se han cuantificado «noticias», ni reseñas ni comunicaciones (trabajos muy breves estos últimos). Un estudio basado en el número de páginas quizá resultaría más representativo, pero también podría dar lugar a distorsiones: hay dos extensas monografías (una de ellas ocupa un tomo completo) de carácter etnográfico, pero son dos casos excepcionales que, de ser cuantificados por su extensión, desnivelarían de forma ficticia la orientación temática de la publicación. 


\section{TEMÁTICA DE LOS ARTÍCULOS PUBLICADOS \\ EN LA REVISTA DE LA SEAEP}

\begin{tabular}{|c|c|c|c|c|c|c|c|}
\hline & A. & E. & P. & & A. & E. & P. \\
\hline 1922 . . . . . . . & 1 & 3 & 6 & $1936-40 \ldots \ldots \ldots$ & 1 & 1 & 5 \\
\hline $1923 \ldots \ldots \ldots \ldots$ & 5 & 1 & 2 & $1941 \ldots \ldots \ldots \ldots$ & 4 & 5 & 9 \\
\hline 1924 ........... & 4 & 4 & 6 & $1942 \ldots \ldots \ldots \ldots$ & 2 & - & 3 \\
\hline $1925 \ldots \ldots \ldots \ldots$ & 4 & 2 & 6 & $1943 \ldots \ldots \ldots \ldots$ & - & 1 & - \\
\hline $1926 \ldots \ldots \ldots \ldots$ & 3 & 5 & 3 & $1944 \ldots \ldots \ldots \ldots$ & 1 & 2 & 1 \\
\hline 1927 . . . . . . . & 3 & 3 & 5 & $1945 \ldots \ldots \ldots \ldots$ & - & - & 1 \\
\hline $1928 \ldots \ldots \ldots \ldots$ & 2 & 2 & - & $1946 \ldots \ldots \ldots \ldots$ & 1 & 3 & 12 \\
\hline 1929 . . . . . . . . & 1 & 1 & 3 & $1947 \ldots \ldots \ldots \ldots$ & 3 & 3 & 6 \\
\hline $1930 \ldots \ldots \ldots \ldots$ & 4 & 2 & 4 & $1948 \ldots \ldots \ldots \ldots$ & 2 & 3 & 11 \\
\hline $1931 \ldots \ldots \ldots \ldots$ & 4 & 2 & 2 & $1949 \ldots \ldots \ldots \ldots$ & 1 & - & 1 \\
\hline $1932 \ldots \ldots \ldots \ldots$ & 2 & 2 & 3 & $1950 \ldots \ldots \ldots \ldots$ & - & 2 & 1 \\
\hline $1933 \ldots \ldots \ldots \ldots$ & 2 & 2 & 1 & $1951 \ldots \ldots \ldots \ldots$ & - & 1 & 1 \\
\hline $1934 \ldots \ldots \ldots \ldots$ & 2 & - & 5 & Total parcial & & & \\
\hline $1935 \ldots \ldots \ldots$ & 1 & - & 8 & 2. etapa ......... & 15 & 20 & 51 \\
\hline Total parcial & & & & & & & \\
\hline 1.“ etapa .......... & 38 & 29 & 54 & TOTAL ......... & 53 & 50 & 104 \\
\hline
\end{tabular}

El cómputo no deja lugar a dudas sobre la orientación de la revista (y de la Sociedad), decantada marcadamente hacia la prehistoria y la arqueología. Pese a esta preponderancia, durante su primera etapa el desequilibrio de temas en favor de la prehistoria será menor que el que se aprecia a partir de 1936-40. Durante los años 20 y primeros 30 la antropología física tiene una importancia muy destacada, debido a la orientación naturalista del principal impulsor inicial de la Sociedad (Manuel Antón) y sobre todo al papel jugado por sus discípulos Francisco de las Barras y Domingo Sánchez, que publican una gran cantidad de trabajos. La etnografía aparece en último lugar, aunque la diferencia que la separa de la prehistoria será bastante menor que la existente en la etapa posterior.

Después de la guerra cambia el panorama. Domingo Sánchez y Francisco de las Barras pasan a un segundo plano y toma las riendas de la Sociedad y la revista Julio Martínez Santa-Olalla, arqueólogo y persona totalmente afín a los nuevos aires políticos, aunque esto, como hemos visto, no le va a servir de mucho en sus deseos de fomentar la Sociedad. La antropología física sufre ahora un importante retroceso con respecto a la etapa anterior, mientras que avanza débilmente la etnografía, aunque se mantendrá muy alejada de la prehistoria. Ésta y la arqueología dominan el campo temático de la revista, hecho que se ve reforzado por la ruptura impuesta por Pérez de Barradas entre el Museo Etnológico y la Sociedad, y el entroncamiento 
de ésta con la cátedra y el Seminario de Historia Primitiva del Hombre, cuyo catedrático es, precisamente, Santa-Olalla.

Es evidente, por tanto, que las Actas y Memorias no tuvieron un interés muy marcado por la publicación de trabajos etnográficos o etnológicos y, en este sentido, su papel como potenciadora de estas disciplinas fue escaso. Sin embargo, no por ello debe dejar de reconocerse la importancia de buena parte de los trabajos etnográficos publicados, de los que hemos hecho una selección en un apéndice de nuestro artículo.

Por lo que se refiere a la Sociedad como institución, es indudable que durante casi toda su vida (y especialmente en sus diez o doce primeros años) gozó de una consideración oficial mucho más importante que la mantenida por la sociedad fundada en 1865 por González Velasco. De todas formas, y como ya hemos indicado en otro lugar, esto no supone que el Estado tuviera plena conciencia de su importancia y la apoyara debidamente. En cuanto a prestigio nacional e internacional, ciertamente lo tuvo. El número y la calidad de los contactos e intercambios mantenidos con centros extranjeros así lo demuestra; en este sentido es destacable la intensa relación mantenida con investigadores portugueses. Este prestigio es semejante al que gozaban buena parte de sus socios, especialmente los que van pasando por su Junta Directiva. El número de dichos socios fue también bastante elevado (hasta 260), así como el de las actividades desarrolladas (sobre todo conferencias) aunque no llegan a organizar ningún congreso. Por lo que se refiere a publicaciones, y además de la revista, debemos referirnos a la ya citada Corona de estudios y, sobre todo, al enorme éxito científico y editorial que supuso la edición de la obra Algunos mitos españoles de Julio Caro Baroja, que pronto agotó los 2.500 ejemplares de la primera edición. También hay que destacar la importante biblioteca que logró formar la Sociedad, sobre todo por intercambios con su revista, cuyos fondos (los reunidos hasta 1942) no pudieron recuperar, pasando a engrosar los del Museo Etnológico.

Para terminar, hagamos una breve valoración final. Lo que hemos indicado sobre el espectro temático de la revista debe aplicarse en idénticos términos al conjunto de actividades de la Sociedad, siempre más enfocada hacia la prehistoria y la arqueología que a la antropología física o la etnografía. Fue precisamente esa orientación arqueológica el origen de los conflictos con el CSIC. No obstante, es evidente que aunque se hubiera centrado en la antropología o la etnografía, Pérez de Barradas habría seguido oponiéndose a ellos -entonces quizá con más razón- desde su dirección del IBS y el Museo. En relación con esto es curioso constatar que durante una decena de años coexisten en Madrid dos centros dedicados (teóricamente) a las ciencias antropológicas en su acepción más general: el IBS y la 
SEAEP, además de quienes se encargaban de ellas en la universidad. Esta duplicidad no sólo no dio lugar a colaboración de ningún tipo, sino que estuvo marcada por un rechazo total entre ambas instituciones, cuyas causas fueron, en buena medida, de índole personal.

Para concluir, debemos reconocer que la SEAEP ayudó considerablemente al desarrollo y consolidación de los estudios arqueológicos y prehistóricos, todo ello en detrimento de la antropología y la etnografía, que sólo en parcelas muy concretas y de la mano de algunos destacados personajes conseguirían resultados positivos.

\section{LUIS ÁNGEL SÁNCHEZ GÓMEZ CSIC, Madrid}

\section{APÉNDICE}

Comunicaciones y memorias de contenido etnográfico publicadas en la revista de la SEAEP*

- Ismael del Pan, «Observaciones a un apunte folklórico de Extremadura», I, 1922, pp. $54-57$ (actas).

- P. Agustín J. Barreiro, «El origen de la raza indígena de las islas Carolinas», I, 1922, pp. 61-65 (actas).

- Ismael del Pan, «Los exvotos de Loja», I, 1922, pp. $72-74$ (actas).

- Luis de Hoyos Sáinz, «Un cuestionario de Demografía etnográfica», I, 1922, pp. 91-95 (actas).

- Luis de Hoyos Sáinz, «Medios naturales o primitivos de transporte en las diversas regiones de España». (Bases para un cuestionario)», I, 1922, pp. 108-118 (actas).

- Luis de Hoyos Sáinz, «Etnografía española. Cuestionario y bases para el estudio de los trajes regionales. (Notas preliminares)», I, 1922, pp. 91-128 bis (mem.).

- Domingo Sánchez y Sánchez, «Nota preliminar relativa al uso de utensilios de piedra en España en el siglo XX», I, 1922, pp. 209-220 (mem.).

- P. Agustín J. Barreiro, «Ensayo de agrupaciones etnográficas en un manuscrito del siglo XIII», II, 1923, pp. 139-150 (mem.).

- P. Agustín J. Barreiro, «La mitología bisaya», III, 1924, pp. 39-46 (mem.).

- Ismael del Pan, «Un curioso amuleto empleado contra el mal de ojo en los borricos de algunas regiones españolas», III, 1924, pp. $47-55$ (mem.).

- Mariano Iñiguez y Ortiz, «Ritos celtibéricos. Las fiestas de San Pedro Manrique», III, 1924, pp. $57-70$ (mem.).

- Juan Uría Ríu, «Sobre la posible influencia de los pueblos musulmanes en la etnogénesis de algunos núcleos de la población asturiana», III, 1924, pp. 139-144 (mem.).

- P. Agustín J. Barreiro, «El olor como carácter de las razas humanas», III, 1924, pp. 153-159 (mem.).

- Ismael del Pan, «Las creencias y supersticiones sobre algunas plantas en la Antigüedad y en nuestros días», III, 1924, pp. 76-86 (actas). 
- P. Agustín J. Barreiro, «Recuerdos de luchas griegas en algunos pueblos de la provincia de Palencia», III, 1924, pp. 89-91 (actas).

- Juan Uría Ríu, «Algunas supersticiones y leyendas relativas a los animales entre los vaqueiros de alzada, en Asturias», III, 1924, pp. 103-108 (actas).

- Ismael del Pan, «De Folklore. Sobre el mito a que debe su nombre la villa guipuzcoana de Mondragón», IV, 1925, pp. 33-43 (actas).

- P. Agustín J. Barreiro, «Algunas referencias sobre la raza malayo-filipina», IV, 1925, pp. $71-80$ (actas).

- Ismael del Pan, «Datos prehistóricos y etnológicos recogidos en algunos pueblos comarcanos en los Montes de Toledo», V. 1926, pp. 43-50 (mem.).

- P. Agustín Melcón, «Notas sobre los ritos fúnebres de algunas regiones del Asia Central», V, 1926, pp. $51-56$ (mem.).

- Domingo Sánchez, "Estilizaciones prehistóricas conservadas en utensilios usados en los tiempos actuales», V, 1926, pp. 57-183 (mem.).

- Francisco de las Barras de Aragón, «Notas de una breve excursión a las Islas Canarias», V, 1926, pp. 211-239 (mem.).

- Emilio Camps Cazorla, «Bailes y juegos populares de Teruel en el siglo Xvilı, VI, 1927, pp. $135-140$ (mem.).

- Fermín Bouza-Brey Trillo, «Prehistoria y Folklore gallegos. Una estación de arte rupestre en las márgenes de la ría de Arousa», VI, 1927, pp. 187-212 (mem.).

- P. César Morán, «Folklore. Creencias sobre curaciones supersticiosas recogidas en la provincia de Salamanca», VI, 1927, pp. 241-261 (mem.).

- Luis Pardo, «La antigua contabilidad de la Comunidad de Pescadores del Palmar (Albufera de Valencia)», VII, 1928, pp. 14-17 (actas).

- Juan Uría Ríu, «Sobre una costumbre nupcial entre los vaqueiros de alzada, de Asturias, desaparecida», VII, 1928, pp. 69-74 (actas).

- P. César Morán, «Arte Popular», VII, 1928, pp. 23-92 (mem.).

- Francisco de las Barras, «Don Francisco de Quiroga, como etnógrafo», VII, 1928, pp. 93-103.

- Tomás López-Tapia Laplana y Eduardo Naval-Galindo Garcés, «Contribución al estudio del Folklore en España y con preferencia en Aragón» [sobre medicina popular], VIII, 1929, pp. 247-257 (mem.).

- Juan Uría Ríu, «Origen probable de la tradición o leyenda que atribuye ascendencia morisca a los vaqueros (sic) de Alzada, en Asturias», IX, 1930, pp. 123-140 (mem.).

- Juan López Soler, «Los hórreos gallegos», X, 1931, pp. 97-161 (mem.).

- P. César Morán, «Datos etnográficos», X, 1931, pp. 198-215 (mem.).

- P. Agustín J. Barreiro, «Un capítulo de la historia inédita de Titaguas, por D. Simón de Rojas Clemente», XI, 1932, pp. 121-135 (mem.).

- José Pérez de Barradas, «El color en la vida y en el arte de los pueblos», XI, 1932, pp. 137-207 y XII, 1933, pp. 3-85 (mem.).

- P. César Morán, «De etnografía antigua y moderna», XIII, 1933, pp. 125-148 (mem.).

- Julio Caro Baroja, «El tocado antiguo de las mujeres vascas. (Un problema de Etnografía)», XV, 1936-40, pp. 33-71.

- Enrique Arqués, «Los yenún», XV, 1936-40, pp. 73-80.

- Marqués de Lozoya, «La vivienda rural en la provincia de Segovia», XV, 1936-40, pp. 151-155.

- Julio Caro Baroja, «Retroceso del vascuence», XVI, 1941, pp. 35-62. 
- Ángel de Tuya, «Cabeza trofeo preparada por los Mundrukús», XVI, 1941, pp. 63 67.

- P. Saturio González, «Industria pastoril en la sierra de Burgos», XVI, 1941, pp. 262-275.

- Juan Álvarez Delgado, «Los aborígenes de Canarias ante la lingüística», XVI, 1941, pp. 276-290.

- Enrique Arqués, «Los yenún. El rey Salomón», XVI, 1941, pp. 291-308.

- P. Francisco de Igualada y P. Marcelino de Castellví, «Musicología de la Amazonia colombiana», XVI, 1941, pp. 309-348.

- Ismael del Pan, «Aspectos etnológico-geográficos de Portugal (Folklore hispanoportugués)», XVIII, 1943, pp. 5-216.

- Elías Serra Rafols, «Las datas de Tenerife», XIX, 1944, pp. 52-69.

- Aquilino González de Pablo, «La secta 'mbueti' o 'mbiti'», XIX, 1944, pp. 70-84.

- Juan Álvarez Delgado, «Sobre la alimentación indígena de Canarias. El gofio. Notas lingüísticas», XXI, 1946, pp. 20-58.

- Enrique Arqués, «El culto a los yenún», XXI, 1946, pp. 59-78.

- Ignacio Bauer, «Las supersticiones en la vida conyugal marroquí, XXI, 1946, pp. 83 . 88.

- P. Saturio González, «Estudio sobre la indumentaria serrana del Partido de Salas de los Infantes (Burgos)», XXII, 1947, pp. 53-58.

- Luis de Hoyos Sáinz, «El método etnográfico en la interpretación prehistórica», XXII, 1947, pp. 67-77.

- Ismael del Pan, "Observaciones sobre la mitología del dragón en España», XXIII, 1948, pp. 44-69.

- Ismael del Pan, «La superstición del 'aojo', plasmada en una manecita de azabache», XXV, 1950, pp. 5-21.

- Carlos Alonso del Real, «Notas sobre animología bubi», XXVI, 1951, pp. 5-16.

(*) Hasta el volumen correspondiente a 1933 se utilizan paginaciones distintas para actas y memorias, por ello indicamos entre paréntesis si se trata de uno u otro tipo de artículo.

La Sociedad Española de Antropología, Etnografía y Prehistoria (1921-1951) fue, hasta la guerra civil, la institución española de mayor relevancia en las materias a las que dedicaba su actividad, especialmente la antropología física y la prehistoria. Se estudia su desarrollo histórico institucional y la orientación científica de su revista, así como las difíciles relaciones mantenidas con el Instituto «Bernardino Sahagún» de Antropología y Etnología del CSIC, que acabarían conduciéndola a su desaparición.

The Spanish Society of Anthropology, Ethnography and Prehistory (1921-1951) was the most important Spanish anthropological institution until the Civil War; however, it was specially interested in Physical Anthropology and Prehistory. A study is made of its historical and institutional development. We analyse too its review and the Society's relations with the «Bernardino de Sahagún» Anthropological and Ethnological Institute. 